NASA Technical Memorandum 88839

\title{
Effect of an Oxygen Plasma on the Physical and Chemical Properties of Several Fluids for the Liquid Droplet Radiator
}

Daniel A. Gulino and Carolyn E. Coles

Lewis Research Center

Cleveland, Ohio

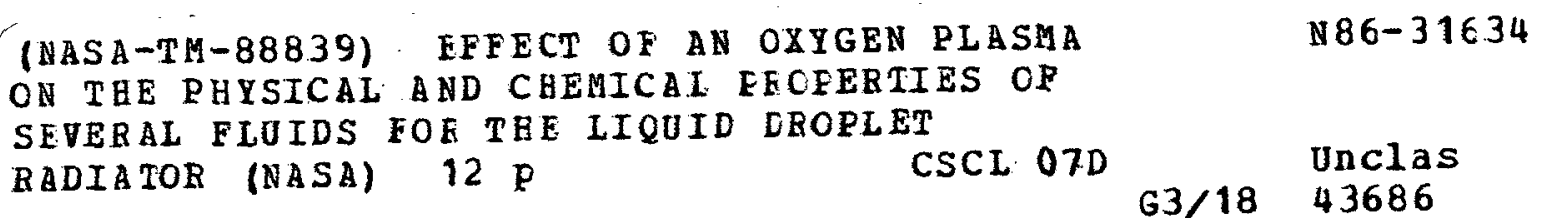

Prepared for the

25th Aerospace Sciences Meeting

sponsored by the American Institute of Aeronautics and Astronautics

Reno, Nevada, January 12-15, 1987 


\section{EFFECT OF AN OXYGEN PLASMA ON THE PHYSICAL AND CHEMICAL PROPERTIES}

OF SEVERAL FLUIDS FOR THE LIQUID DROPLET RADIATOR

Daniel A. Gulino and Carolyn E. Coles

National. Aeronautics and Space Administration

Lewis Research Center

Cleveland, Ohto 44135

\section{SUMMARY}

The Liquid Droplet Radiator is one of several radiator systems currently under investigation by NASA Lewis Research Center. It involves the direct exposure of the radiator working fluid to the space environment. An area of concern is the potential harmful effects of the low-earth-orbit atomic oxygen environment on the radiator working fluid. To address this issue, seven candidate fluids were exposed to an oxygen plasma environment in a laboratory plasma asher. The fluids studied included Dow Corning 705 Diffusion Pump Fluid, polymethylphenylsiloxane and polydimethylsiloxane, both of which are experimental fluids made by Dow Corning, Fomblin 225, made by Montedison, and three fluids from the Krytox family of fluids, Krytox 143AB, 1502, and 16256, which are made by Dupont. The fluids were characterized by noting changes in visual appearance, physical state, mass, and infrared spectra. of the fluids tested, the Fombin and the three Krytoxes were the least affected by the oxygen plasma. The only effect noted was a change in mass, which was most likely due to an oxygen-catalyzed depolymerization of the fluid molecule.

\section{INTRODUCTION}

The Advanced Radiator Program at NASA Lewis is currentiy investigating the Liquid Droplet Radiator (LDR) for potential use by spacecraft power systems. This concept uses a radiator fluid (in the form of small drops ejected from an orifice plate) directly exposed to space as its heat 
transfer medium. The LDR has several potential advantages, among these are a large radiator surface area per unit mass, invulnerability to puncture by small particles, and ease of stowage and deployment. ${ }^{1}$ In order for such a system to be feasible, several problems must be resolved. These include droplet loss, spacecraft contamination, and fluid degradation in the space environment.

Any fluid proposed for use in the LDR must meet several requirements. Among these are: (1) high emissivity, for optimum radiator cooling, (2) low solar absorptivity, (3) a surface tension high enough to induce rapid droplet formation but low enough to inhibit wetting of the orifice and collector surfaces, (4) low viscosity, to minimize pump power requirements, and (5) low vapor pressure, to minimize fluid losses and possible spacecraft contamination through evaporation.

In addition to the above requirements, any proposed fiuid must also survive the space environment to which it will be exposed. At low-earth-orbit (LEO) altitudes (generally 180 to $650 \mathrm{~km}$ ), the principal chemical specie is neutral atomic oxygen, ${ }^{2}$ which is highly reactive. At proposed space station orbttal altitudes, atomic oxygen impacts spacecraft surfaces with an energy of about $4.25 \mathrm{eV}$. Since the radiator fluid in the LOR system would be directly: exposed to the LEO environment, it must be able to successfully withstand this atomic oxygen exposure. This paper is concerned with the effect of the lowearth-orbit atomic oxygen environment on several candidate radiator fluids.

Seven fluids were chosen for this study. They were selected on the basis of availability, fluid family (e.g., silicone-based oil, and perfluorinated, carbon-based 0il), viscosity, and vapor pressure. The flutds selected included: (1) pentaphenyltrimethyltrisiloxane (Dow Corning 705 Diffusion Pump Fluid), (2) polymethylphenylsiloxane (PMPS, an experimental fluid made by Dow 
Corning), (3) polydimethylsiloxane.(PDMS, another experimental fluid made by Dow Corning). (4) Fomblin 225, a perfluoropolyether made by Montedison, (5) Krytox 143AB, (6) Krytox 1502, and (7) Krytox 16256: Fluids.5 to 7 are from the Krytox. line of perfluoropolyether. $011 \mathrm{~s}$ made by DuPont. These: candidate, fluids cover a wide range of values for viscosity and vapor pressure, as shown in Table 1. Bruce Ulissi and Earl Sommers of. DuPont provided us with much useful information.

\section{EXPERIMENTAL PROCEDURE}

Fluid samples were exposed to the simulated low-earth-orbit environment by placing a small quantity ( 1 to $7 \mathrm{~g}$ ) of each fluid in separate $10 \mathrm{ml}$ beakers and then placing the beakers. inside the reaction chamber of a Structure Probe, Inc. Plasma-Prep II ${ }^{\ominus}$ plasma asher. The exposed fluid surface area was $3.8 \mathrm{~cm}^{2}$. This device creates a plasma environment by passing a carrier. gas (in this case, ambient air) over the samples and exciting the gas with $100 \mathrm{~W}$ of continuous wave RF power at $13.56 \mathrm{MHz}$. The operating pressure is about $50 \mu \mathrm{m}$. While it is difficult to calculate a direct relationship between exposure time in the asher under these conditions and lifetime in LEO, use of the asher does allow gross determination of the likelihood of survivability of a particular material in LEO.

Several different kinds of measurements were made on the fluid samples as a function of time of exposure to the plasma. All fluids were examined by infrared spectroscopy, which is highly sensitive to chemical structure, before and at regular intervals during exposure to the plasma. Where such spectra were not featureless, uv-visible spectra were obtained as well. In addition to the spectroscopic measurements, changes in mass, physical state, and visual appearance were noted. 
RESULTS AND DISCUSSION

For the purpose of discussion, the fluids will be divided into three categories, based on their chemical composition. The DC 705 will be discussed individually, the PMPS and POMS will be discussed together, and the Fomblin 225 and three Krytox fluids will also be discussed as a group.

Dow Corning 705

of the seven fluids tested, the asher plasma environment had its greatest effect on the $O C$ 705. The fluid, which was initially a clear, colorless, odorless liquid of moderate viscosity, rapidly (in less than $10 \mathrm{hr}$ of exposure) became a clear, lavender colored, high viscosity liquid with a rather sweet odor. Changes in color and viscosity became apparent after:only a few hours of exposure. After $66 \mathrm{hr}$ of exposure, the fluid had almost solidified. An approximately $2 \mathrm{~g}$ sample showed an increase in mass of about 3.5 percent during this time.

A comparison of IR spectra taken prior to exposure and then after $43.5 \mathrm{hr}$ of exposure indicated several changes (Fig. 1). The presence of a new, broad peak centered at about $3400 \mathrm{~cm}^{-1}$ is a strong indication of hydroxy functional groups. The exact nature of these functional groups was not determined. Any water or low molecular weight alcohol or acid would have evaporated off under vacuum. (No attempt was made to collect and analyze any volatile products.) One likely explanation is that these new functional groups are attached to a much larger molecule, possibly the parent compound itself. The small increase in mass supports this conclusion. The chemical structure of Dow Corning 705 is shown below.

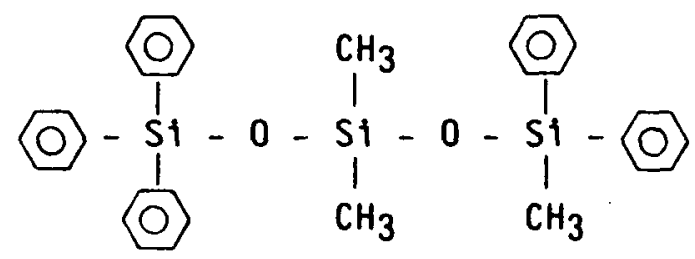


The broad, relatively weak peak centered at about $1700 \mathrm{~cm}^{-1}$ suggests the presence of carbonyl groups. This would be consistent with the presence of esters, ketones, or carboxylic acids. In addition, the sweet odor noted above also indicates the possible presence of ester groups. Regardless of the exact structure, it is clear that the DC 705 undergoes significant degradation, including significant oxidation, when exposed to the plasma environment.

\section{PMPS and POMS}

The plasma environment also had significant effects on PMPS and PDMS. After $43.5 \mathrm{hr}$ of exposure, each fluid had developed a film of solid material both on the walls of the beaker and across the top of the fluid itself. A very small gain in mass (less than 0.3 percent) was noted for each fluid over this exposure time. Both fluids remained clear and colorless. Spectroscopic data yielded little information. Infrared spectra taken before and after exposure for both PMPS and POMS showed no differences. Ultraviolet spectra obtained on the PMPS also showed no changes. The solidified material most likely results from an oxygen-catalyzed polymerization of these materials, perhaps by a crosslinking between substituents on individual molecules. The chemical structures of PMPS and PDMS are shown below.

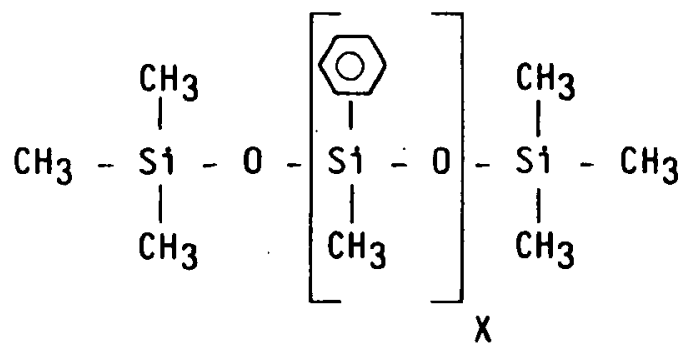

$$
\begin{aligned}
& x=7-10
\end{aligned}
$$


Fomblin 225 and the Krytoxes

The Fomblin 225 and the three Krytox fluids showed the least detrimental effects from exposure in the plasma asher. No changes were noted in clarity or color. No changes of any kind were noted in the IR spectra of these fluids, even after many (160 to 380 ) hours of exposure. The only effect of the plasma noted was a slow, linear loss in mass for each fluid. Figure 2 shows the mass loss versus time for two of the fluids, Fomblin 225 and Krytox 143AB. The calculated mass loss fluxes for Fomblin 225 and the Krytoxes are given in Table 2 .

An attempt was made to determine the exact cause of the observed mass losses. Under the conditions in the plasma asher, the fluids are exposed to a vacuum of approximately $50 \mu \mathrm{m}$ and a temperature of about $50 \mathrm{C}$, in addition to the plasma. It was thought that perhaps either the vacuum or the vacuum in conjunction with the elevated temperature might be responsible for the observed mass loss. To this end, one sample each of Fomblin 225 and Krytox $143 A B$ were exposed to vacuum conditions at both room temperature and $50 \mathrm{C}$ No mass losses were observed for either fluid when exposed to these special conditions. (This is not surprising, since these are vacuum pump oils and are specifically designed to withstand this kind of environment.) clearly, the plasma environment causes the mass loss. The oxygen may react with the fluids, but only to form one or more volatile products. The chemical structures for Fomblin 225 and the Krytoxes are shown below. 


$$
\begin{gathered}
{\left[-\mathrm{CF}_{2}-0-\mathrm{CF}_{2}-0-\right]_{n}} \\
\text { and } \\
{\left[-0-\mathrm{CF}_{2}-\mathrm{CF}_{2}-\right]_{n}}
\end{gathered}
$$

(random mixture)

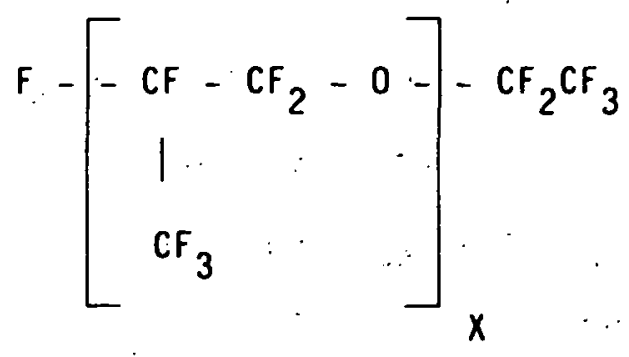

$$
\begin{aligned}
X & =7 \text { to } 9 \text { for Krytox } 1502 \\
& =21 \text { to } 23 \text { for Krytox } 143 \mathrm{AB} \\
& =64 \text { to } 66 \text { for Krytox } 16256
\end{aligned}
$$

The most probable explanation for these observed mass losses is an oxygencatalyzed depolymerization of the parent molecule. The ether $\alpha$-carbon at the ends of the molecules is the most likely point of attack. The resulting fragments are then evaporated away, leaving no change in the remaining fluid.

\section{RECOMMENDAT IONS}

The results presented herein indicate that, as a general class, the perfluoroethers are acceptable as atomic oxygen durable candidates for use in the LDR. By this, it is meant that these fluids showed no physical or chemical changes upon exposure to an atomic oxygen environment. In most instances, the measured mass loss fluxes were quite low. If the proper combination of vapor pressure and viscosity could be found in a perfluoroether (two of the fluids tested here, Krytox 143AB or Fomblin 225 , might be satisfactory), the mass loss problem could be overcome by maintaining a sufficientiy large reservoir onboard the spacecraft to replenish the circulating fluid as necessary. Additional studies must be made to determine if these fluids have the other requisite properties (emissivity, etc.) described earlier. 


\section{REFERENCES}

'Taussig, R. T. and Mattick, A. T., "Droplet Radiator Systems for Spacecraft Thermal Control," Journal of Spacecraft and Rockets, Vol. 23, No. 1, Jan. - Feb. 1986, pp. 10-17.

2U. S. Standard Atmosphere, 1976. U. S. Government Printing office, Washington, D.C., 1976. p. 30 . 
TABLE 1. - PROPERTIES OF CANDIDATE LIQUID OROPLET RADIATOR FLUIOS

\begin{tabular}{|l|l|c|c|}
\hline \multicolumn{1}{|c|}{ Flutd } & $\begin{array}{c}\text { Vapor pressure } \\
\text { at } 20{ }^{\circ} \mathrm{C}, \\
\text { torr }\end{array}$ & $\begin{array}{c}\text { Molecular } \\
\text { weight, } \\
\text { amu }\end{array}$ & $\begin{array}{c}\text { V1scosity } \\
\text { at } 20^{\circ} \mathrm{C}, \\
\text { CS }\end{array}$ \\
\hline OC 705 & $3 \times 10^{-10}$ & 546 & 175 \\
PMPS & $6 \times 10^{-7}\left(120^{\circ} \mathrm{C}\right)$ & 1300 & 148 \\
POMS & $3 \times 10^{-8}\left(120^{\circ} \mathrm{C}\right)$ & 2700 & 25.4 \\
Fomb 1 in 225 & $3 \times 10^{-12}$ & 9500 & 355 \\
Krytox 143AB & $5 \times 10^{-6}$ & 3700 & 230 \\
Krytox 1502 & $5 \times 10^{-7}$ & 1465 & 17 \\
Krytox 16256 & $5 \times 10^{-14}$ & 17000 & 2560 \\
\hline
\end{tabular}

table 2. Calculated mass loss fluxes of FOMBLIN ANO KRYTOX FLUIDS

\begin{tabular}{|c|c|}
\hline Fluid & $\begin{array}{l}\text { Mass loss flux } \\
g m \times \mathrm{cm}^{-2} \mathrm{hr}^{-1}\end{array}$ \\
\hline $\begin{array}{l}\text { Fomblin } 225 \\
\text { Krytox } 143 \mathrm{AB} \\
\text { Krytox } 1502 \\
\text { Krytox } 16256\end{array}$ & $\begin{array}{l}1.38 \times 10^{-5} \\
0.977 \times 10^{-5} \\
2.84 \times 10^{-3} \\
2.79 \times 10^{-5}\end{array}$ \\
\hline
\end{tabular}




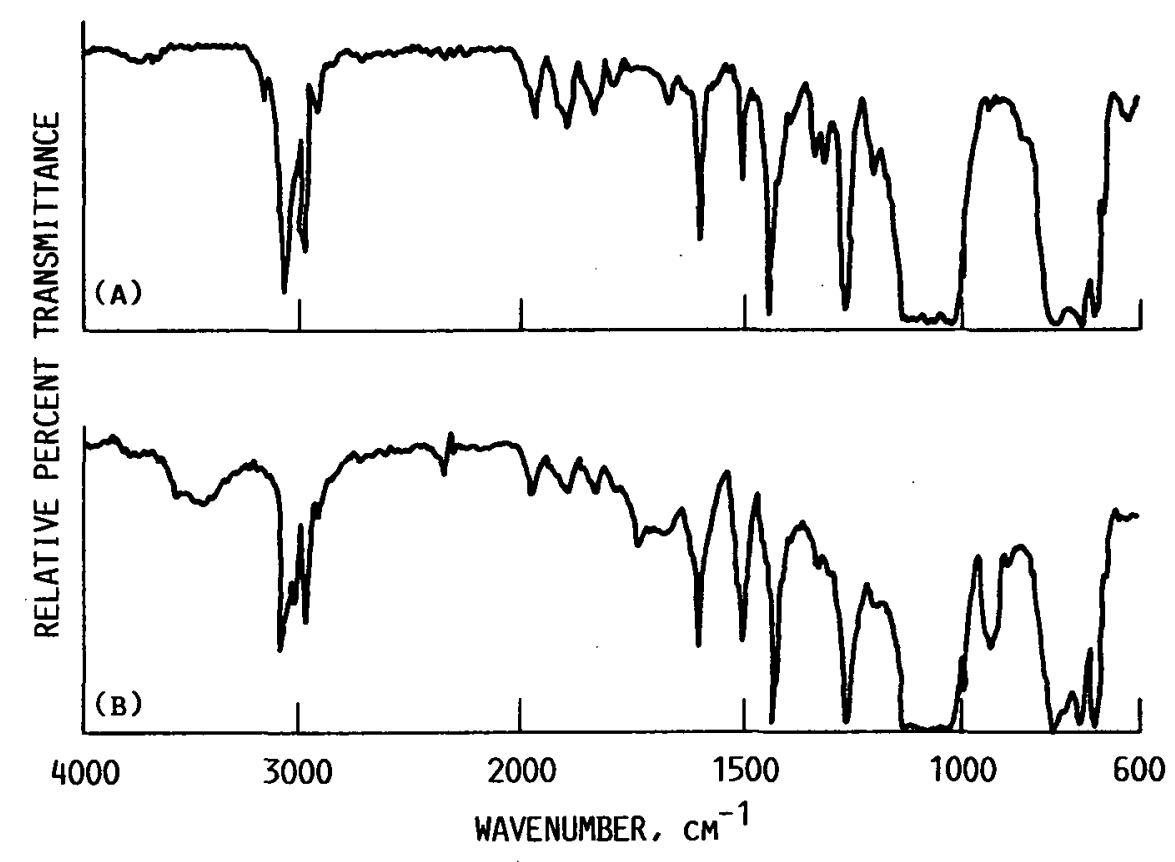

Figure 1

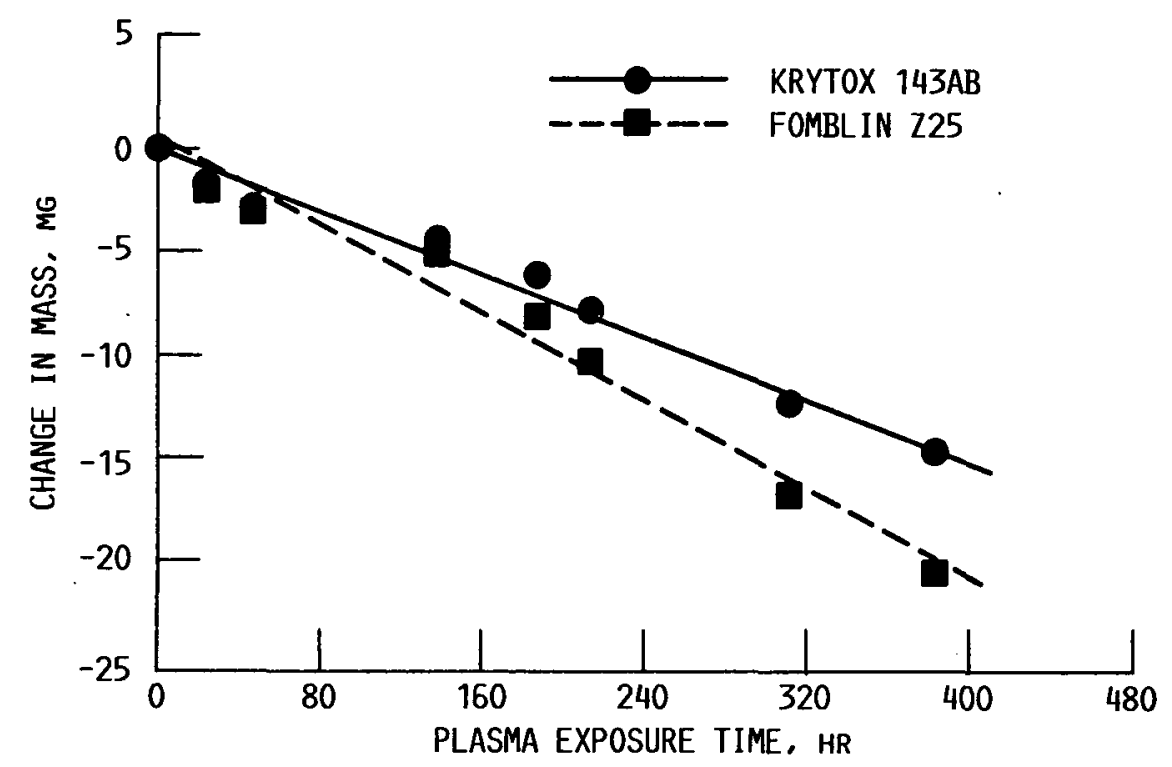

FIGURE 2 


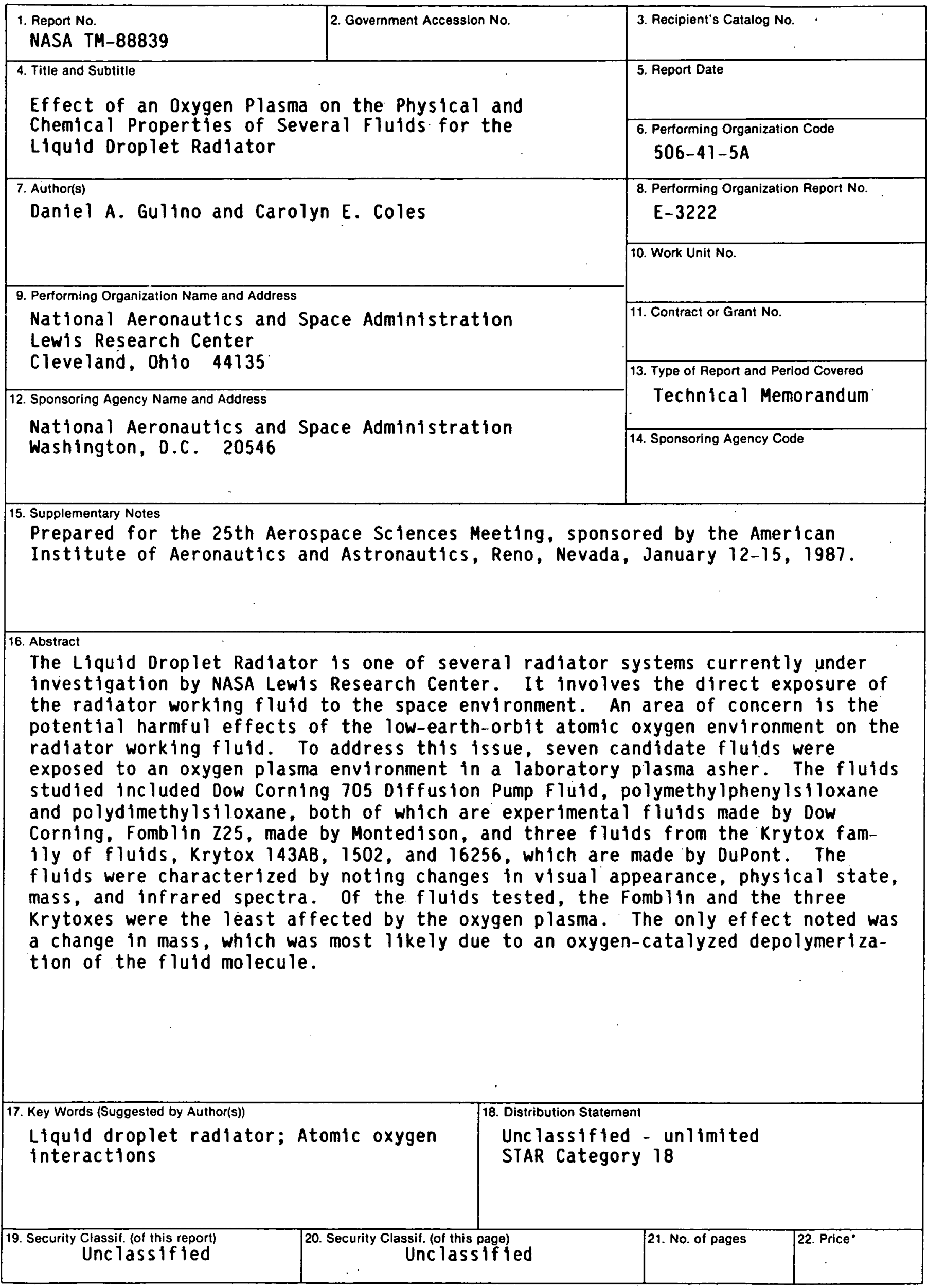


National Aeronautics and Space Administration

Lewis Research Center

Cleveland. Ohio 44135

Official Business

Penaly for Prtvate Use $\mathbf{5 3 0 0}$
SECOND CLASS MAIL

ADDRESS CORRECTION REQUESTED

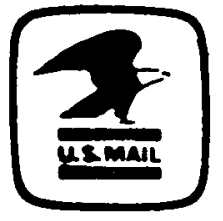

Postage and Fees Paid National Aeronautics and

Space Administration NASA-451 